\title{
Authorship in science: A critical analysis from a Foucauldian perspective
}

\author{
Carla Mara Hilário ${ }^{1, *}$, Daniel Martínez-Ávila ${ }^{1}$, Maria Cláudia Cabrini Grácio, \\ and Dietmar Wolfram²
}

${ }^{1}$ São Paulo State University (UNESP), Av. Hygino Muzzi Filho, 737, Marília (17525-900), São Paulo, Brazil and ${ }^{2}$ School of Information Science, University of Wisconsin-Milwaukee (UWM), P.0. Box 413, Milwaukee, WI 53201, USA

*Corresponding author. Email: hilariopesquisa@gmail.com

\begin{abstract}
This article aims to contribute to the discussion on authorship in contemporary science from Foucauldian and Kuhnian perspectives, highlighting the social aspects of science and the role of authorship in scientific revolutions. Thus, it describes the functions of the 'author' discussed by Foucault that can assist to reveal the characteristics of the scientific practice and examples of how theories are materialized. As a result, it identifies the ways in which modern science is developed and how knowledge is construed by multiple authors, group authors, the merit that is attributed by citations, etc. This article highlights the complexity of authorship attribution and the need to rethink generalized bibliometric techniques to evaluate science considering other aspects that go beyond the mere listing of the authors.
\end{abstract}

Key words: authorship; Foucault; Kuhn; sociology of science; scientometrics

\section{Introduction}

Research on the conception of authorship in science has often focused on the formal characteristics and legal aspects of the term, treating the attribution of authorship as an indication of ethical and moral responsibility for knowledge creation and its attribution. Although the context of the creation of scientific works has a direct influence on their development, the sociological aspects that are inherent to the construction of a scientific work have been commonly overlooked in the research on authorship. Social factors underlying the work (such as the authors' motivations for the development of the study), the collective interest in a particular research topic, and the efforts made to produce new knowledge have been the catalysts of new work dynamics and characteristics for contemporary science, although they have not received careful attention from scholars.

It is assumed that the social influence in the development of science is still at the processes of design and construction of knowledge, as this is not directly acquired but mediated by external elements such as the context in which the author is immersed, the social and economic environment, the policies of the scientific field, and the culture and tradition of the academic community.

The identity of the author, especially constituted by his/her personality and his/her scientific and social capital, also influences his/ her way of working and the process of construction of knowledge, as it represents the author's perspective and critical view that is from his/her life experiences, education, academic trajectory, and previous knowledge.

Thomas Kuhn's 'The Structure of Scientific Revolutions' (Kuhn 1970), highlighted the importance of the psychosocial conditions that permeate science, as he understood that to know a science it is necessary to know its practices and functions, i.e. to know the behavior of the scientists, their actions, and their decision-making that result from their own cognitive norms, formed during the life trajectories of the group of researchers working on that science. In the second edition of his book, Kuhn defined 'paradigm' as 'the entire constellation of beliefs, values, techniques, and so on shared by the members of a given community' (p. 175). This sociological sense has important implications for our discussion on authorship.

The circumstances related to the time and space of the research can also influence the characteristics and outcome of a work, as well as the work of the collaborators, reviewers, and critics who contribute to the improvement and even redirection and re-dimension of the initial idea or objective.

In this vein, our study aims to contribute to the critical reflection on the question of authorship in contemporary science from a different point of view from the dominant one in the current scientific discourse. Here we are working with a notion of discourse that resembles 'knowledge formations, entities that provide an effective and limited perspective for producing knowledge about a topic' 
(Talja et al. 2005: 89). We use the theoretical framework proposed by the French philosopher Michel Foucault, who discussed the concept of author in his work 'What is an author?' (1984, originally written in 1969 in response to the also discussion on the new role of authorship in science by Roland Barthes, 'The Death of the Author', 1967). Contrary to Barthes' view in which the process of 'writing' was meant to replace the author as an arbitrary creator, Foucault's notion of authorship raised awareness of the function of the author as a classificatory element that may initiate a scientific discourse including other authors. In this vein, the author would function as a sign of the discourse. Elsewhere, Foucault (1998, originally published in 1967: 272) had stated that authors such as 'Marx, Freud, and Nietzsche profoundly modified the space of distribution in which signs can be signs'.

We believe that there is a need to revive the reflections on the sociological aspects of the attribution of authorship in scientific publications, given the changes and transformations in the identity of the notion of authorship in contemporary science. We continue a discussion on authorship in science (Yang et al. 2017), using a Foucauldian framework (Budd and Moulaison 2012; Moulaison et al. 2014; Martínez-Ávila et al. 2015) and discourse analytic techniques (Budd and Raber 1996; Talja et al. 1997; Talja et al. 1998; Talja 1999; Budd 2006; Martínez-Ávila 2012; Martínez-Ávila and Fox 2015). Foucault's philosophical views on science are revisited and applied to the current conception of authorship, contributing to the discussion and understanding of this complex phenomenon. Foucault's work significantly contributes to the social studies of science with his critiques of social institutions, theories about power and the complex relationship between power and knowledge, the expression of discourse, and the studies of identity which are essential to understand the scientific practice. In this context, it is important to highlight the influence and collaborations in the process of construction of knowledge, as well as the aspects related to the Sociology of Science.

\section{First acts of attribution of authorship}

The word 'author' comes from the Latin word 'auctor'. An author can be a person or entity responsible for the invention, creation, and development of a product that in the case of scientific works, results from studies, reflections, and analyses. The concept of the 'author' emerged in the scientific discourse, although still not in the modern sense, with the foundation of the first scientific journals in 1665 ('Journals des sçavans' and 'Transactions of the Royal Philosophical Society').

Since then, he meaning of the term 'author' has been shaped and has been the object of discussion, reflection, and debates of important scholars, especially during the twentieth century. There have been several divergences and controversies in the attempt to reach a consensus on what it really means to be an author, and how to act in the process of authorship attribution taking into consideration the sociological, cultural, and ethical factors that are intrinsic to this process.

The authorship of literary, scientific, and artistic works has always been recognized and considered an important practice in terms of authority and acceptance since antiquity. However, during the period before the Renaissance, literary texts (including narratives, short stories, epics, tragedies, comedies, and the like) were accepted and put into circulation without any authorship indication. In these cases, legitimacy and originality of the text were guaranteed from the alleged antiquity of the work. On the other hand, as Foucault (1984) points out, the scientific texts, which mostly involved studies on Cosmology, Medicine, Natural Sciences, and Geography, were not accepted in the Middle Ages without an authorship indication, as they only carried a value of Truth when explicitly marked with the name of its author, revealing, at that time, the importance of the attribution of authorship in science.

In ancient times, the attribution of authorship was not equated to the ownership of an immaterial property, i.e. there was not a legal status of authorship as a commodity. The origins of the concept of copyright date back to 1710 when the British Parliament adopted the first 'copyright' act known as the 'Statute of Anne' (see for instance Lessig 2004, for a very sharp account of the genealogy of copyright), while according to the current director of the Stanford Program in Law, Science and Technology, Mark Lemley (cited in Stallman 2006), 'the widespread use of the term "intellectual property" is a fashion that followed the 1967 founding of the World "Intellectual Property" Organization (WIPO), and only became really common in recent years'. The use of the term 'intellectual property' entailed several problems in Law and also for the construction of the concept of the author, as it suggests thinking about the copyright aspect of authorship, patents, and trademarks all together in analogy with the property of physical objects. According to Stallman (2006), the use of this term misrepresents the nature of the issue and misleads legislators to change the laws to assimilate copyright issues into a material exploitation of ideas that suits the interests of the companies that exercise copyright, patent, and trademark powers. The analogy of a material exploitation of ideas can be translated to the legal justification for the restriction to access to scientific works (especially in digital formats) exerted by publishers and providers of academic journals. (In fact, this argument could be linked to Richard Stallman's (2001) note published by Nature entitled 'Science Must Push Copyright Aside'.) As one might guess, these restrictions have more to do with economic interests and less with a legitimate prevention from accessing to materials of dubious quality or veracity (as it should be responsibility of information mediators of every kind), i.e. legitimization of knowledge.

The first acts to establish the identity of authorship appeared in the Middle Ages, as a strategy to identify the authors of works prohibited by the censorship of the time. The texts began to identify their authors as the discourses became transgressors with punishable origins. Discourses were designated as an act, in the sense of being placed 'in the bipolar field of the sacred and the profane, the licit and the illicit, the religious and the blasphemous' (Foucault 1984: 108). This meant that they were subject to being condemned for transgressing the religious or political orthodoxy of the time (Cavalheiro 2008).

Between the seventeenth and eighteenth centuries, scientific texts became valid because of their connection to a systematic set of (re-) demonstrable truths that focused more on the replicator and less on their original author, thus leading to an omission of the author's function (Foucault 1984). In this context, the importance of citations increased as a way of proving and guaranteeing the information reliability presented in the scientific works of the time, not necessarily in terms of the authority of writer of the work but by means of replication or the possibility of being replicated. Scientific works began to receive recognition from peers on the condition of being the results of established and systematically demonstrated truths, or when they were embedded in organized theoretical and methodological systems. 
At the end of the eighteenth century and beginning of the nineteenth century, transgression would be resumed when the conception of the author began to be incorporated into the property system that is characteristic of Modern Society. In this context, a regime of ownership of texts, rules on copyright, reproduction, etc., was established as a form of control exercised by capitalism, as well as a form of punishment for those who infringe intellectual property rights. This new conception of authorship as a commodity has been increasingly gaining importance at the same pace capitalism has been advancing during the past centuries.

In the twentieth century, researchers such as Roland Barthes, Michel Foucault, Giorgio Agamben, and Mikhail Bakhtin discussed removing the privilege given to the architect of writing, and choosing language instead as the main criterion for the attribution of authorship, assuming that a work only becomes effective or exists when it is written and transformed into language (Azevedo Neto 2014). The case of Bakhtin is worth noting because of his distinctive views on the dialogical communication defined by the author as an interaction between texts as a consequence of 'polyphony'. That is, for Bakhtin there is a correlation between similar or close discourses both at the moment of the construction of knowledge (when a work is written) and at the moment in which the scientific work is read. For Bakthin, 'Any understanding of live speech, a live utterance, is inherently responsive ... Any utterance is a link in the chain of communication' (Bakhtin 1986: 84). This means that the Speech Genres are always conditioned by the existence of a text. The combination of representative elements of materiality provides a meaning and a semiotic dimension that shapes the text or becomes part of a system. In other words, it is an element that carries values in a society or culture and its participation enables the chain of discursive communication that gives it singularity.

In 'The death of the author' (Barthes 1967), Barthes criticizes the relationship between the author's life and the text, stating that it is the language and not the author who speaks in a work. According to Barthes, the author is a modern construction and positivism gave authorship an excessive importance in a time of overestimation of the individual prestige. The author would just be responsible for mixing the writings by many, making a collage of different texts in a way that one text refers to another in a process of infinite intertextuality.

In Barthes' view, the text is a fabric of citations, resulting from many cultural sources in a way that the multiplicity of meanings is gathered in the act of reading. The interaction between the text and the reader is what guarantees the meaning of the text, rather than a meaning that is transmitted through a one-way channel originating with the author.

By transposing the relationship between writing and reading, Barthes proposes an equation between author and reader in a way that both the author and the reader are producers of the text, both are 'writers'. However, for the birth of the reader to take place, the death of the author must occur. With the removal of the author, there would not be anybody to whom an identity can be attributed, that is everything that could be established based on the author's nomination is disseminated, it gets in contact with other texts and other voices (Cavalheiro 2008).

As for scientific production, it could be said that Barthes' views resemble the citation system, as he claims that every scientific study is associated with ideas, concepts, theories, methods, studies, and analyses that were previously conducted to fill gaps or to complement or contrast theories. In this sense, as Antonio put it, 'authorship and citations have the purpose of allowing the genealogy of the text itself and its authors to be traced, [permitting] the verification and validation of the methods that are used and the results that are achieved' (Antonio 1998: 190, in translation).

In a scientific work, citation plays an important social role and can indicate the association of the work to theoretical or methodological schools as well as underlying epistemological, linguistic, and rhetorical aspects. In this case, citation expresses a positive reception of the cited work. On the other hand, citation can express a neutral reception or a negative reception from the scientific community, as a critique or rejection of the cited work (Glänzel 2006; Lima et al. 2012; Catalini, Lacetera and Oettl 2015). However, scientific literature has showed that researchers tend to ignore minor works and so when a significant part of a scientific community engages in the effort of formally criticizing a work, it must be of some substance (Garfield 1979a). In addition, theoretically, self-citations can be considered a form of self- promotion. However, the self-citation practice is common and considered reasonable provided the self-citations do not represent a large proportion of the citations made. Some studies show that at least $10 \%$ of all citations are self-citations (Garfield 1979b), with even higher rates reported more recently, depending on the time period studied after the publication of self-cited works (Aksnes 2003).

\section{Scientific authorship}

In recent years, the issue of scientific authorship has attracted the attention of scholars in light of the increase of collaborative research in all fields of knowledge. In this context, co-authorship is justified as a strategy to ease the achievement of the proposed objectives in relation to the access to material and intellectual resources and speed in the production of knowledge.

The practice of collaborative research has also become more common internationally, by increasing the size of the research groups, overcoming the geographical limitations among their members, and expanding the cultural diversity and the possibility of partnerships (Ortoll et al. 2014). For Luukkonen et al. (1992), collaboration among researchers enhances both professional growth and increased knowledge, as this process offers access to material and information resources as well as the possibility of association with scientific elites (especially increasing the visibility of young scientists).

Scientific collaboration is often confused with co-authorship, as observed by Hilário (2015) when analyzing the perception of equivalence between the terms 'scientific collaboration' and 'coauthorship' for researchers in Mathematics, Dentistry, and Information Science in Brazil. Scientific collaboration represents a contribution in the form of comments, suggestions, indications of literary references, and even reviews, without, necessarily, participating in the elaboration of the work. The collaboration of an individual can change the entire structure of the work, but this does not mean that this individual should assume the role of an author. Co-authorship serves as evidence of the significant intellectual collaboration-such as contributing original ideas to the research, expertise, resources, or knowledge that would not allow the project to be carried out otherwise-and assumes that the efforts of the collaborators warrant their inclusion as authors. Otherwise, there may not be formal evidence of collaboration, beyond perhaps acknowledgements. 
To be an author, the individual must actively participate in the development of the study and fulfill all the criteria recommended by the instruction manual of good scientific practices that governs a certain scientific fields, especially taking responsibility for the publication content. In this context, we highlight the importance of questioning the authorship process in works with multiple participants, since the roles and responsibilities of each author could considerably decrease as the size of the team increases.

According to Lozano (2014), the authorship credit and the merit responsibility are diluted in co-authored publications, with a reduction in the relative contribution of each one of the many author (in case of many authors) and the threshold for authorship attribution. The growing concern with hyper-authorship, where hundreds of authors may be listed on a single publication, is relatively novel because authorship issues were not problematic in previous times when most works were single-authored. We can say that the big science problem mentioned by de Solla Price (1963) is a characteristic of today's collaborative environments that author attribution has become more problematic. Thus, minor contributions, such as technical services, editing and review, and borrowing resources from more prestigious researchers could be considered sufficient to warrant co-authorship. This phenomenon can be observed in journals that request the indication of each author's contribution in the paper, sometimes listing these contribution types (Yang, Wolfram and Wang 2017). The acknowledgement of author's contributions to the research has become more important as research teams have grown in size. This has led to hyper-authorship cases, where authorship credit is given to dozens or even hundreds of researchers (Cronin 2001).

The attribution of authorship and co-authorship in science is done by the authors themselves, who tend to follow disparate criteria given the diversity of the structural dynamics of the scientific fields and the specific needs of the nature of each research. Some codes of ethics and manuals suggest guidelines to facilitate the identification of authors in collaborative research and propose behavior 'patterns' to standardize the process of authorship and coauthorship attribution.

While analyzing the conditions for granting authorship in Spanish journals, Ruíz-Pérez et al. (2014) identified that many journals adopt style manuals of the International Associations of Science and Technology. However, they point out that the information on the author's functions that is provided to the researchers is not always clear, so in the end it is up to the editors to deal with this process according to the guidelines of the area of the journal. Ruíz-Pérez et al. also highlight the importance and relevance of the standards recommended by the Committee on Publication Ethics-COPE (Albert and Wagner 2003) and the Vancouver group guidelines (ICMJE 2017). These guidelines would be applicable in many cases beyond the medical publications, and have therefore been adopted by several international journals, including the areas of Science and Humanities.

The International Committee of Medical Journal Editors (ICMJE), one of the main groups of scientific journal editors in Medicine, recommends that authorship in science should be based on four criteria that must be fulfilled together: substantial contributions to the conception or design of the work; or the acquisition, analysis, or interpretation of data for the work; drafting the work or revising it critically for important intellectual content; final approval of the version to be published; and agreement to be accountable for all aspects of the work in ensuring that questions related to the accuracy or integrity of any part of the work are appropriately investigated and resolved (ICMJE 2017). Those who are listed as authors must meet all four authorship criteria and all who meet the four criteria should be identified as authors. Those who do not meet all four criteria should just be recognized as collaborators in the acknowledgments section (Wiley 2014). One must emphasize that such situations are mainly aimed at scientific practice, as they deal with the legal concerns of the attribution of authorship, including accountability and legal responsibilities. For instance, the authorship criteria and contributions of the JAMA Network (2017) family of journals, based on the ICMJE's guidelines, also state that 'one or more authors should take responsibility for the integrity of the work as a whole, from inception to published article' (see http://jamanetwork. com/journals/jama/pages/instructions-for-authors).

Although there are also guidelines for authorship in widely used manuals and style guides such as the American Psychological Association (APA), Chicago Style, and the Brazilian Association of Technical Norms (ABNT), scientific behavior is dependent on the culture and tradition of the scientific community in which these authors are immersed. This means that there is no universal consensus on the aspects that determine the status of a co-author or a collaborator in a scientific work. The practice of scientific collaboration and co-authorship also involves ethical and moral aspects. Like the veracity of the content is also the moral responsibility of the authors, the indication of authorship should also be their responsibility.

\section{The concept of authorship from a Foucauldian perspective}

Foucault discussed the conception of authorship in his lecture entitled 'What is an author?' given at the Collège de France in 1969. Foucault did not focus too much on a historical-sociological analysis of the author, but rather spoke on 'the relationship between text and author and with the manner in which the text points to this "figure" that, at least in appearance, is outside it and antecedes it' (Foucault: 105).

The answer to the question 'how important is the author?' posed by Foucault, represents the basis of his speech, as this question entails that writing suffices for itself and unfolds infinitely until it leads to the disappearance of the subject.

Azevedo Neto (2014) comments that while classical Greece writing immortalized heroes, in modern societies the author plays the role of the dead in the game of writing. For Foucault, authors such as Flaubert, Proust, and Kafka are examples of 'effacement of the writing subject's individual characteristics' (Foucault 1984: 102).

Foucault emphasizes that the conception of the author is closely related to the notion of work. Both are complex concepts. According to Foucault, the problem about the concept of work consists in its own identification. There is no rule about what a work consists of and what features and elements it must contain. $\mathrm{He}$ states: 'How can one define a work amid the millions of traces left by someone after his death? A theory of the work does not exist, and the empirical task of those who naively undertake the editing of works often suffers in the absence of such a theory' (Foucault 1984: 104). In spite of the advances in Library and Information Science to develop a 'work theory' (Smiraglia 2001) and the discussions on the standardization of the relationships between works (expressions, manifestations, and items), and persons and corporate bodies responsible for intellectual or artistic endeavors in FRBR (Functional 
Requirements for Bibliographic Records) (studied in relation to Foucault by Budd and Moulaison 2012; Moulaison et al. 2014), continuous research has revealed the persistency of historical and practical problems (Smiraglia et al. 2010, 2011; Smiraglia and Lee 2012; Martínez-Ávila et al. 2015). Given the complexity of the concept of a work, erasing the existence of the author and limiting only to his/her work is not enough.

The notion of writing preserves the existence of the author. 'When rigorously applied, this notion should allow us not only to circumvent references to the author, but also to situate his recent absence' (Foucault 1984: 104). Foucault adds that we must locate the space left empty by the author's disappearance, follow the distribution of gaps and breaches, and watch for the openings that this disappearance uncovers (p. 105).

By analyzing the work in relation to the author, Foucault emphasizes that the author's name serves to characterize a certain mode of being of discourse, that is for a discourse, the fact that there is an author's name indicates that the discourse is not an ordinary speech, but rather, it is a word that must be received in a certain mode and that it must, in a given culture, receive a certain status. Foucault adds that the author's name 'is not simply an element in a discourse (capable of being either subject or object, of being replaced by a pronoun, and the like); it performs a certain role with regard to narrative discourse, assuring a classificatory function. Such a name permits one to group together a certain number of texts, define them, differentiate them from and contrast them to others' (p. 107)

The indication of authorship represents more than the origin of a work or the idea of ownership, it confers credibility in relation to the techniques and experiences used for the elaboration of the work. The name of the author guarantees a certain status to the work, whether in the authorship attribution or in the citation process. This process of authorship and recognition through citation leads to greater 'credibility capital', which in turn leads to further recognition and more opportunities to work with other influential researchers (Latour and Woolgar 1986). Latour and Woolgar point to the importance of the laboratory as a system where scientists collaborate and ultimately turn speculative statements into scientific facts through discovery and discourse.

The author function is the characteristic of the mode of existence and circulation and functioning of certain discourses within a society. It appeared at the end of the eighteenth century, according to Azevedo Neto (2014), when the profit from property reached the field of literature, too. The association of the work with the author occurred as a way to 'control' the discourses and to identify and punish the transgressors.

While considering only the author of a book or text, Foucault characterized the author function in at least four aspects: first, as an appropriation mechanism, officially characterized as a repressive function for those authors transgressing the established order; second, by the possibility of establishing the veracity of the scientific information and the origin of the text; third, for the construction of the rational being called author, the constructor of the discourse; and fourth, for the distinction and dispersion of the numerous 'I's' (selves) that might appear in the text under the same aspect.

In scientific practice, the first characteristic of the author's function can be translated not only to discussions on open access and copyright holding of the academic works but mainly to the legal and moral responsibilities in the cases of plagiarism, falsification of data, retractions, etc. In this vein, while scientists rarely make a profit from their publications, dishonest practices are subject to severe academic punishment by peers and institutions.

The second characteristic has a clear implication for scientific practice (as Foucault himself distinguishes between literary works and scientific works). Foucault gives examples of the historical transformations of the acceptance of truth. While in the Middle Ages an argument was only accepted when marked with the name of their author (e.g. 'Hippocrates said', not necessarily as an argument from authority but as statement of demonstrated truth by the markers), in the seventeenth and eighteenth centuries a reversal occurred in which scientific discourses began to be received for themselves, in the anonymity of an established or always redemonstrable truth' (p. 109). The author's name only served to christen the theorem and to indicate the practice of redemonstrated truth, and not necessarily to refer to the individual who originally produced it. Today, it can be argued that the democratization of the means of scientific production, academic egos, and requirements for evaluation (including games of citations, questionable practices, etc.) and the recognition of peers have restored the importance of the author sometimes in an exaggerated way. For instance, people do not simply conduct discourse analysis but they also need to clarify if it is a Foucauldian discourse analysis, a Critical Discourse Analysis according to Fairclough, etc. The author does not only serve to identify the methodology or theoretical approach but mainly to legitimize its validity in light of the ascription to a school of thought (regardless of the content).

The third characteristic of the author function may be related to the process of construction of the author's knowledge, his/her ideologies, paths, and training as an individual. This idea is in line with Kuhn's (1970), as the scientists' conduct is a result of cognitive norms, including their experiences, ideologies, and their formation as social individuals. On the other hand, Foucault states that the attribution of a discourse to an individual is not spontaneous. This means that it takes time to identify the discourse of an author and one can be confused by contradictory doctrines or works attributed to a same author (many times in different moments of his/her career). It is normal for authors to hold different views and epistemological positions in different moments of their career. Not only do young scholars mature and change their views in time but also senior scholars can pass through different phases. Joseph Tennis (2008), for instance, identified the different epistemic stances of the works of Birger Hjørland in different moments, from materialist through activity-theoretic to critical realist viewpoints. What is the real function of the name 'Hjørland' (author) in his oeuvre? Is his discourse represented only by his later works? Foucault himself, who was questioned for changing his approach over time (from 'Madness and Civilization' to 'The Archeology of Knowledge' and to 'The History of Sexuality', Gauntlett 2008: 125-6) acknowledged this transformation by his own work: 'Well, do you think I have worked like that all those years to say the same thing and not to be changed?' (Foucault 1982: 131). Does it mean that there is no unity in the discourse of these authors and the author's name cannot function as an indicator of their work? This aspect is even much more complex in the current scientific scenario of multiple co-authorships. How does one distinguish and ascribe one paper written as co-authors to the oeuvre of a given author? Are the contributions of the different coauthors assimilated to the views of any of them in a homogeneous way during the very same time that they collaborate or decide to coauthor a paper? Would the explicit statement of the contribution of 
each author help to clarify this author's function in these cases? Of course, these are questions that require much more scrutiny.

Finally, and perhaps related to these questions, the fourth characteristic considered the dispersion of the selves. 'The self that speaks in the preface to a treatise on mathematics and that indicates the circumstances of the treatise's composition- is identical neither in its position nor in its functioning to the self that speaks in the course of a demonstration, and that appears in the form of "I conclude" or "I suppose"' (Foucault 1984: 112). Of course Foucault referred to the different selves in the speech of a single author in space and time (as Foucault came from the Humanities tradition of single authorship and sadly he did not engage in co-authorship). In the case of multiple authors, this aspect can be also related to egos and the personalities of the authors that are expressed in the text (such as the distinctive vocabulary, writing style, etc., as well as the critical views and epistemological stances that might be impressed). Should perhaps the different paragraphs or parts of a scientific text be introduced by their statement of authorship? Although interesting, this is of course a very unlikely possibility for several reasons. According to Foucault, the author is not only the individual that elaborates a text or a work: there are also transdiscursive authors that create theories, traditions, academic disciplines, etc. In this case, the author function exceeds the work itself. From the discourses they created, Freud and Marx established innumerable possibilities for the emergence of new discourses. Foucault calls them initiators of discursiveness. Foucault reports that Marx and Freud developed concepts and analysis techniques that are appropriate and receptive beyond their own discourses, opening space for new ideas and theories based on their texts.

Freud's works did not create a science, but the scientific discourse uses these works as a coordinate system. Thus, Freud's and Marx's texts end up under the optics of a researcher, modifying psychoanalysis itself and Marxism. The relationship between the author and his/her text will not be identical to the relationship that the adepts of this founding knowledge will engage with his/her works. The author function does not classify only texts but also works and disciplines.

The originators of a discourse play a fundamental role in the development of a scientific field or discipline. This process also resembles the idea of normal science and paradigm shift proposed by Thomas Kuhn (1970) that characterizes scientific progress as revolutions happening by leaps rather than in a continuous line.

However, for some later writers the shift from one paradigm to another may be more gradual. Kuhn claims that the transition between theories occurs through 'revolutions' as a form of questioning the previous theory and that between these transitional periods there is a 'normal science', which consists on research based on one or more past scientific achievements recognized by the scientific community as the foundation of its later practice during this time.

In this context, science is developed through paradigms, which are presuppositions of science. Paradigms are recognized scientific achievements that, for some time, provide problems and model solutions for a scientific community. A paradigm is governed by a group of practitioners, rather than being governed by an object of study. Therefore, it is not the method that creates the paradigm, but rather it is the paradigm that specifies the research techniques to be employed and the research questions studied.

At some point in the paradigmatic phase of a theory, there will be an absence of critical imposition, which will only return to the scene when a 'crisis' erupts. Thus, a scientific revolution begins when a paradigm goes into a 'crisis', that is when there is a loosening of the paradigm norms due to the accumulation of scientific problems. During the transitional period from a crisis paradigm to a new one, the cumulative mode of knowledge production ends, and thus, at this stage, there is a reconstruction of the area of study from the adoption of new epistemological principles, and from the assumption of other anthological commitments in such a way that, by the end of the transitional period, scientists will have broadly modified their view on a particular object of study (Oliva 1994).

The adoption and then abandonment of the neurosurgical procedure of Lobotomy can be considered as a paradigmatic transition example. It is a technique that was used to treat severe schizophrenia cases, and whose developer was awarded the 1949 Nobel Prize. Although this technique was a success in the mid-1940s, its practice resulted in a large number of victims with irreversible consequences. This led to studies on new techniques and the advent of the first antipsychotic drugs that ultimately turned lobotomy into a prohibited technique. In this case, there was a shift from the current paradigm, leading to the emergence of new treatment methods, such as the use of drugs with sedative effects and behavioral therapies.

There are cases that a change in the studied object definition can cause a discourse change, as in the Pluto case, that used to be classified as a planet until August 2006 when the International Astronomical Union (IAU) redefined it as a dwarf planet, together with some asteroids, based on new knowledge. Hjørland (2013) mentions the Pluto example as the confirmation of the fallibilism principle associated with Popper and Peirce and treats the scientific knowledge claims as invariably vulnerable truths. This means that current theories are only tentatively and constantly altered as new allegations are proven and accepted by the scientific community and that this the way that knowledge should be organized (classified) in our systems.

During the crisis period there may be resistance to the adoption of the new paradigm, as such a change implies a new world view and the necessity of restructuring knowledge and social structures (in addition to the uncertainty of the forthcoming paradigms). During this period of paradigmatic crisis, authorship is a fundamental element. In addition to offering reliability in the new discourse, as a classificatory function as Foucault points out, it is also possible to identify the formation of schools of thought, or discourses, that attack the scientific problems of the paradigm, causing a scientific revolution with new assumptions that will be probably be caused by the authors involved in the process.

It should be noted that a paradigm shift only happens if there is an acceptable and vigorously justified theory. This is the reason why the complexity of authorship and of what is behind the creation process, the act of becoming the author of an idea or theory, is so important during the period of scientific revolutions.

Kuhn also points out the importance of the manuals, as well the language (definitions, terminology, approaches) before and after a revolution, as they perform the function of recording the articulated knowledge of what is accepted by a community at a given time, and help to shape the paradigm or world view. In this way, as noted by Vieira and García-Fernandéz (2006), the manual is the purest expression of normal science and plays an important role in its development, as it records the stable result of past revolutions. However, a typical manual or textbook does not need to provide truthful information about how these bases were initially recognized, as well as their precursors, and later adopted by science. The texts that govern the new normal practice following the revolution must abolish 
the old tradition and emphasize the new developments. This characteristic means that, unless the researcher has experienced the scientific revolution in life, she/he will probably not be able to perceive the magnitude of the change and lose part of the history of his/her own science (Vieira and García-Fernandéz 2006).

This criticism by Kuhn in relation to the manuals indicates that the essence of authorship is lost in that type of document; they are, however, important for the construction of scientific knowledge during this period, as they are mainly used by novice researchers.

Based on the above, it can be stated that the emergence of new scientific paradigms occurs in the process of founding discursivity, in which the authors produced more than one work, and created the possibility and the rules of formation of other texts, and thus they established the infinite possibility of discourses. These founding discourses made possible the creation of new ideas, theories, and analyses that are different from what they already expounded and, yet, they belong to what they have founded. According to Leite (2009), the key difference would be in the founding of discursivity, giving the founding act a unique in relation to the later productions.

The attribution of discursive authors in Foucault is applied to the cases in which the works contribute to the formation of new topics (discourses), such as great discoveries or theories that reformulate the area, or propose new methods and techniques as well as basic concepts for a field.

In the case of Lobotomy, the founders of discursivity (of the following paradigm, the antipsychotic or anti-psychiatry movement) would be the authors who questioned this practice and proposed a new form of treatment using sedative drugs, that is a new discourse. This new paradigm, that today would certainly not be considered very efficient, but it allowed the creation of other drugs, more effective ones, with more precise effects, without side effects, etc. The new discourse allowed the creation of new discourses, although they are not always cited in the later discourses ('unlike the founding of a science, the initiation of a discursive practice does not participate in its later transformations' (Foucault 1984: 116). The founders of Lobotomy are not necessary cited in the papers discussing the current paradigm; however, there would not be a current paradigm or discourse without Lobotomy and antipsychotics.

Other classical examples of paradigmatic revolutions are the substitution of Ptolemy's geocentric theory in Astronomy, in which the earth was the center of the universe, for Copernicus's heliocentric theory, Newton's theory in Physics superseded by Einstein's theory, and the revolution in Chemistry with Lavoisier. In all cases the historical references or genealogies of a discourse are not always acknowledged in the form of citations. On the other hand, it can also be observed that in scientific periods prior to the contemporary science, great scientific advances (especially those caused by paradigmatic revolutions) are identified with individual authors, such as 'Euclidean Geometry', 'Aristotelian Logic', 'Copernican heliocentrism', 'Boyle's Chemistry', 'Lavoisier's Chemical Revolution', 'Einsteinian physics', 'Maxwell's electromagnetic theory', and many others. These transdiscursive authors are being acknowledged in every use of the discourse they founded, although their original works are not being counted in the form of citations. For example, a paper on library classification can state that Melvil Dewey based his first edition of the Dewey Decimal Classification on Aristotelian Logic or Hegelian idealism. While the first edition of the Dewey Decimal Classification is likely to be cited, it would not be a requirement for the authors to cite the original writings of Aristotle or Hegel.
In modern science, there are also controversies regarding the individual identification of the authorship in scientific advancements. For instance, historians of Chemistry have questioned the revolutionary status of Lavoisier's work, stating that the contribution of Lavoisier's predecessors and successors have not received enough recognition in the historical narratives (Oki 2004). They also point out the insufficient credit that was given to Lavoisier's collaborators in the elaboration of his own works.

This aspect becomes more evident in contemporary science, given the important role of scientific teams for scientific advance. In some areas, it is necessary to contribute with very specialized theoretical knowledge from different areas, or sharing material resources and equipment. One example would be the discovery of the Higgs boson particle, which can be considered a new landmark in the development of Physics. Although the particle is named after Peter Higgs, who contributed with important predictions and discussions in papers authored in the 1960's, the empirical confirmations in the present decade are attributed to team of scientists from different nationalities affiliated to the CERN (European Organization for Nuclear Research) research center. It is common to see papers authored by some of these teams such as ATLAS collaboration or CMS collaboration. Thus, in contemporary science, in several areas of knowledge, the merit of scientific advancement (in terms of publications) has been associated with a research group rather than one single researcher and authorship.

In this context, the relevance of a new perspective is emphasized when studying scientific behavior in areas of knowledge in which scientific practice is not a lonely exercise but a cooperative work. In this sense, the issue of the attribution of authorship would focus on the contribution of individuals (researchers) and the attribution of scientific merit, also in regard to citations. In a high-impact scientific paper, can we identify its main topic or point of view with the second, third, or fourth co-author of the paper? In those cases in which the most cited paper of an author is one in which she/he is the second, third, or fourth co-author, can we primarily associate that author to the topic or the discourse of the paper?

For Foucault (1984: 111), an author is defined as 'a field of conceptual or theoretical coherence', and in this vein, if we analyze the author as a domain, it is possible to identify his/her association (or dissociation) with the work. As there are also individuals who collaborate with material resources and technical skills that are listed as authors as a form of reward for the contribution, the theme or concepts of the work and their coherence with the oeuvre of the authors might be a good variable for the analysis of their real presence in a particular work. Another option would be the analysis of the style, school of thought, or epistemological stance of parts or the whole work in relation to those of the individual authors. Of course, in this case we would be also dealing with same problems of dispersion of selves that were discussed by Foucault for the case of different works authored by a single author.

According to Foucault (1984: 116), within these fields of discursivity, there is the necessity for a 'return to the origin', a return that would not be to the author but a return to the text itself, more specifically, to a primary and unadorned text with a particular attention to those things that are said in the interstices of the text, the gaps, and the absences. A return is needed to the empty spaces that have been masked by omission or concealed in a false and misleading plenitude. In 'Fantasia of the library' (Foucault 1977, originally published in 1967), he has stated 'The imaginary is not formed in opposition to reality as its denial or compensation; it grows among 
signs, from book to book, in the interstice of repetitions and commentaries; it is born and takes shape in the interval between books. It is a phenomenon of the library' (p. 91). In this sense, Foucault admits that the author function is extremely complex, especially when one tries to analyze this function in broader sets such as oeuvres and scientific disciplines. To overcome this complexity, he proposes a discourse analysis ('a historical analysis of discourse') of the modes of existence, that is the whole context of the discourse. Thus, in light of the complexity of the discourse, he proposes a return to the original question of the author in relation to the work, omitting the role of the subject as an originator and analyzing it as a variable and complex function of discourse: 'under what conditions, and in what forms can something like a subject appear in the order of discourse? What place can it occupy in each type of discourse, what functions can it assume, and by obeying what rules?' (Foucault 1984: 118).

As far as the Sociology of Science is concerned, the attribution of authorship is also present in the citation system for the construction of knowledge, as it can be considered a social organization composed of information exchange by recognition (Hagstrom 1965). Sharing scientific knowledge is not only fundamental to the recognition of the researcher's talent but it is also considered a moral and ethical obligation, since scientific advances depend on the collaboration between past and present generations, as new knowledge is always derived from previous knowledge (Merton 1973; Droescher and Silva 2014).

Many works and authors that are considered essential for the development of a scientific area or discipline are not mentioned or cited in the publications of that discipline. This phenomenon, known as Obliteration by Incorporation (Merton 1988), happens when the initial idea in a founding theory becomes common knowledge and the mention of its origin is dispensable. It is also worth noting that the founding authors are not always the initiators of discursiveness. According to Foucault (1984: 115), in the case of science, 'the act that founds it is on an equal footing with its future transformations; this act becomes in some respects part of the set of modifications that it makes possible'.

Moreover, it is possible that the citing author presents ideas that are construed from the sum of his studies and readings, and for this reason, there is not one specific source but several sources that inspired the construction of knowledge. The combination of knowledge in science allows a consensus of ideas, knowledge shared by several individuals, and thus the determination of which authors inspired each passage of the citing work is almost an impossible task.

On the other hand, it is also possible to identify the school of thought and epistemological stance of the work based on the attribution of the authorship of the work itself and the citations. Within the Foucauldian framework, this aspect would be a consequence of the classificatory function of the author, and the status that this name gives to the work.

Finally, although Foucault presented the idea of the dissociation between the individual as a writer and the function of author, a complex task, the thesis that underlies Foucault's text is that the birth of the author takes place through several intermediaries, such as publishers, reviewers, other authors, and even by the readers. Thus, the delimitation of what would be an author (and therefore should be attributed) becomes even more complex when considering the internal and external variables of the creation process.

\section{Conclusion}

In science, Foucault's conception of author offers a broad vision of the process of construction of knowledge, considering contextual aspects such as the historical-sociological moment of the development of the work or discipline, the events that interfered in this process, as well as the influence of reviewers, editors, and peers of scientific works. Thus, it is considered that the conception of author in science goes beyond the act of writing a scientific work, but it involves several elements that are internal and external to the intellectual field, and, when combined, produce a unique and authentic discourse.

In the face of the various contextual aspects of science, including the cultural characteristics and the ethical aspects of academia, the determination of what or who is a (co-)author of a given work is as difficult a task for those who must attribute the authorship, especially for the authors of collaborative studies. In addition, the criteria for authorship tend to vary from field to field, usually depending to the nature of the research and the traditions of the scientific field in relation to contributions, collaborations, and co-authoring practices.

In this article, we revealed that the authorship of a scientific work, in some cases, may not represent the true authors of that discourse formation, based on the elements and author functions discussed by Foucault. The way in which modern and contemporary science works, with knowledge construed by multiple authors, group authorships, attribution of merit from citations, and omissions of merit in the form of common knowledge, reveals the complexity of the authorship attribution and the need to rethink the bibliometric techniques that are used to evaluate science. One step in this direction would be consideration of other contextual aspects (an idea that is yet to be explored).

Therefore, we conclude that the difficulty in conceptualizing an author in science stems from the complexity in defining the roles and functions of an author, especially in multiple authorship and group authorship. In these cases, shared and fragmented work is an obstacle for clear and strict criteria for the attribution of co-authorship, especially when little significant contributions for the development of the study or academic politics exist.

In this context, we believe that more scientific policies need to be studied and developed considering the complexity of the construction of discourses. These would also contribute to better scientific evaluations and richer understandings of the scientific behavior of researchers in the process of the construction of knowledge.

\section{Acknowledgements}

The authors would like to thank an anonymous reviewer for the helpful comments.

\section{References}

Albert, T., and Wagner, E. (2003) 'How to Handle Authorship Disputes: A Guide for New Researchers'. The COPE report. < https://publicationethics. org/files/2003pdf12.pdf $>$ accessed 2 July 2017.

Antonio, I. (1998) 'Autoria e cultura na pós-modernidade', Ciência da Informação, 27/2: 189-92.

Aksnes, D. (2003) 'A Macro Study of Self-Citation', Scientometrics, 56/2: 235-46.

Azevedo Neto, J. (2014) 'A noção de autor em Barthes, Foucault e Agamben', Floema. Caderno De Teoria e História Literária, 10: 153-64. 
Bakhtin, M. (1986) Speech Genres and Other Late Essays. Mcgee, V. W. (Trans.). Austin, TX: University of Texas Press.

Barthes, R. (1967) 'The Death of the Author', Aspen Magazine, 5/6:

Budd, J. (2006) 'Discourse Analysis and the Study of Communication in LIS', Library Trends, 55/1: 65-82.

Budd, J. M., and Moulaison, H. L. (2012) 'Foucault and the bibliographic universe: What really is an author?', Poster presented at the ASIST 2012 Annual Meeting, October 27-31, Baltimore, MD.

Budd, J., and Raber, D. (1996) 'Discourse Analysis: Method and Application in the Study of Information', Information Processing and Management, 32/1: 217-26.

Catalini, C., Lacetera, N., and Oettl, A. (2015) 'The Incidence and Role of Negative Citations in Science', PNAS, 112/45: 13823-6.

Cavalheiro, J. S. (2008) 'A Concepção de autor em Bakhtin, Barthes e Foucault', Signum: Estudos De Linguagem, 11/2: 67-81.

Cronin, B. (2001) 'Hyperauthorship: A Postmodern Perversion or Evidence of a Structural Shift in Scholarly Communication Practices?', Journal of the Association for Information Science and Technology, 52/7: 558-69.

de Solla Price, D. J. (1963), Little Science, Big Science, New York: Columbia University Press.

Droescher, F. D., and Silva, E. L. (2014) 'O pesquisador e a produção científica', Perspectivas Em Ciência Da Informação, 19/1: 10-189.

Foucault, M. (1977) 'Fantasia of the Library', in Bouchard, D. F. and Simon, S. (trans) Language, Counter-Memory, Practice, pp. 87-109. Ithaca, NY: Cornell University Press.

Foucault, M. (1982) 'The Subject and Power', in Dreyfus, H. L. and Rabinow, P. (eds) Michel Foucault: Beyond Structuralism and Hermeneutics, 2nd edn, pp. 208-26. Chicago: University of Chicago Press.

Foucault, M. (1984) 'What is an Author?', in Rabinow, P. (ed.) The Foucault Reader, pp. 101-120. Pantheon Books: New York, NY.

Foucault, M. (1998) 'Nietzsche, Freud, Marx', in Faubion, J. D (ed.) Aesthetics, Method, and Epistemology, pp. 269-78. New York: The New Press.

Garfield, E. (1979a) 'Is Citation Analysis a Legitimate Evaluation Tool?', Scientometrics, 1/4: 359-75.

Garfield, E. (1979b) 'Perspective on Citation Analysis of Scientists', in Garfield, E. (ed.) Citation Index - Its Theory and Application in Science, Tecnhnology and Humanities, pp. 224-52. Philadelphia: Isi Press.

Gauntlett, D. (2008) Media, Gender and Identity: An Introduction, 2nd edn. London: Routledge.

Glänzel, W. (2006) 'A Concise Review on the Role of Author Self-Citations in Information Science, Bibliometrics and Science Policy', Scientometrics, 67/2: 263-77.

Hagstrom, W. (1965) The Scientific Community. New York: Basic book.

Hilário, C. M. (2015) 'A presença da colaboração científica em pesquisas brasileiras: um estudo nas áreas de Ciência da Informação, Matemática e Odontologia', Master's thesis, Information Science of São Paulo State University - UNESP, Marília, São Paulo.

Hjørland, B. (2013) 'Theories of Knowledge Organization-Theories of Knowledge', Knowledge Organization, 40/3: 169-81.

ICMJE. (2017) Defining the Role of Authors and Contributors. $<$ http://www. icmje.org/recommendations/browse/roles-and-responsibilities/defining-therole-of-authors-and-contributors.html> accessed 5 July 2017.

JAMA Network (2017) Instructions for Authors. <http://jamanetwork.com/ journals/jama/pages/instructions-for-authors html $>$ accessed 29 September 2017.

Kuhn, T. (1970) The Structure of Scientific Revolutions Second Edition, Enlarged. Chicago: University of Chicago Press.

Latour, B., and Woolgar, S. (1986) Laboratory Life: The Construction of Scientific Fact, 2nd edn. New Jersey: Princeton University Press.

Leite, N. V. A. (2009) 'Foucault com Lacan: o que é "um retorno a ..."', in Souza, P., Gomes, D. O. (orgs) Foucault com outros nomes, pp. 167-176. Ponta Grossa: UEPG.

Lessig, L. (2004) Free Culture: How Big Media Uses Technology and the Law to Lock Down Culture and Control Creativity. New York: Penguin Press.
Lima, R. A., Velho, L. M. L. S., and Faria, L. I. L. (2012) 'Bibliometria e "avaliação" da atividade científica: um estudo sobre o índice h', Perspectivas Em Ciência Da Informação, 17/3: 3-17.

Lozano, G. A. (2014) 'Ethics of Using Language Editing Services in An Era of Digital Communication and Heavily Multi-Authored Papers', Science and Engineering Ethics, 20: 363-77.

Luukkonen, T., Persson, O., and Silvertsen, G. (1992) 'Understanding Patterns of International Scientific Collaboration', Science, Technology, and Human Values, 17: 101-26.

Martínez-Ávila, D. (2012) 'Problems and Characteristics of Foucauldian Discourse Analysis as a Research Method', in Smiraglia, R. P., and Lee, H.-L. (eds) Cultural Frames of Knowledge, pp. 99-110. Ergon: Würzburg.

Martínez-Ávila, D., and Fox, M. J. (2015) 'The Construction of Ontology: A Discourse Analysis', in Smiraglia, R. P., and Lee, H.-L. (eds) Ontology for Knowledge Organization, pp. 99-110. Ergon: Würzburg.

Martínez-Ávila, D. et al. (2015) 'What is an Author Now? Discourse Analysis Applied to the Idea of an Author', Journal of Documentation, 71/5: 1094-114.

Merton, R. K. (1973) [1942] 'The Normative Structure of Science'. in Merton, R. K. (ed.) The Sociology of Science: Theoretical and Empirical Investigations. Chicago: University of Chicago Press.

Merton, R. K. (1988) 'The Matthew Effect in Science. II. Cumulative Advantage and the Symbolism of Intellectual Property', ISIS, 79: 606-23.

Moulaison, H. L., Dykas, F., and Budd, J. M. (2014) 'Foucault, the Author, and Intellectual Debt: Capturing the Author-Function Through Attributes, Relationships, and Events in Knowledge Organization Systems', Knowledge Organization, 41/1: 30-43.

Oki, M. C. M. (2004) 'Paradigmas, Crises e Revoluções: A história da Química na Perspectiva Kuhniana', Quimica nova escola, 20. <http://qnesc. sbq.org.br/online/qnesc20/v20a06.pdf $>$ accessed 5 July 2017.

Oliva, A. (1994) 'O normal e o revolucionário na reprodução da racionalidade científica', in Portocarrero, V. (organ.) Filosofia, história e sociologia das ciências I: abordagens contemporâneas. Rio de Janeiro: Fiocruz.

Ortoll, E. et al. (2014) 'Principales parámetros para el estudio de la colaboración científica en big science', Revista Española De Documentación Cientifica, 37/4: e069.

Ruíz-Pérez, R., Marcos-Cartagena, D., and Delgado López-Cózar, E. (2014) 'La autoría científica en las áreas de ciencia y tecnología. Políticas internacionales y prácticas editoriales en las revistas científicas españolas', Revista Española De Documentación Científica, 37/2: e049.

Smiraglia, R. P. (2001) The Nature of a Work: Implications for the Organization of Knowledge. Lanham, MD: Scarecrow Press.

Smiraglia, R. P., and Lee, H.-L. (2012) 'Rethinking the Authorship Principle', Library Trends, 61/1: 35-48.

Smiraglia, R. P., Lee, H.-L., and Olson, H. A. (2010) 'The Flimsy Fabric of Authorship', in Ménard, E., Nesset, V., and Mas, S. (eds) Information Science: Synergy Through Diversity: Proceedings of the 38th Annual CAIS/ACSI conference, June 2-4, pp. 1-5. Montreal, Quebec: Concordia University; Toronto: CAIS.

Smiraglia, R. P., Lee, H.-L., and Olson, H. A. (2011) 'Epistemic Presumptions of Authorship', in iConference 2011, Inspiration, Integrity, and Intrepidity, pp. 137-143. New York: ACM.

Stallman, R. M. (2001) 'Science Must Push Copyright Aside', Nature Web Debates. <http://www.nature.com/nature/debates/e-access/Articles/stall man.html> accessed 5 July 2017. Reprinted in Stallman, R. M. (2015) Free Software, Free Society Selected Essays of Richard M. Stallman Third Edition. pp. 83-86, Boston, MA: Free Software Foundation.

Stallman, R. M. (2006) 'Did You Say "Intellectual Property"? It's a Seductive Mirage', Policy Futures in Education, 4/4: 334-6. Reprinted in Stallman, R.M. (2015) Free Software, Free Society Selected Essays of Richard M. Stallman Third Edition. pp. 124-126, Boston, MA: Free Software Foundation.

Talja, S. (1999) 'Analyzing Qualitative Interview Data: The Discourse Analytic Method', Library and Information Science Research, 21/4: 459-77.

Talja, J. et al. (1998) 'Discourse Analysis of User Requests', Communications of the ACM, 41/4: 93-4. 
Talja, S., Heinisuo, R., Luukkainen, S., and Järvelin, K. (1997) 'Discourse Analysis in the Development of a Regional Information Service', in Proceedings of the 2nd British-Nordic Conference on Library and Information Studies. Queen Margaret College, Edinburgh, pp. 109-28.

Talja, S., Tuominen, K., and Savolainen, R. (2005) 'Isms" in Information Science: Constructivism, Collectivism and Constructionism', Journal of Documentation, 61/1: 79-101.

Tennis, J. T. (2008) 'Epistemology, Theory, and Methodology in Knowledge Organization: Toward a Classification, Metatheory, and Research Framework', Knowledge Organization, 35/3-2: 102-12.
Vieira, J. S., and Garć́a-Fernandez, R. (2006) 'A estrutura das revoluções científicas na economia e a Revolução Keynesiana', Estudos Econômicos, 36/2: 355-81.

Wiley, J. (2014) The Best Practices Guidelines on Publishing Ethics. A Publisher's perspective, 2nd edn. New Jersey: John Wiley \& Sons. <http:// media.wiley.com/assets/7324/10/Best-Practice-Guidelines-on- PublishingEthics-2ed.pdf $>$ accessed 5 July 2017.

Yang, S., Wolfram, D., and Wang, F. (2017) 'The Relationship Between the Author Byline and Contribution Lists: A Comparison of Three General Medical Journals', Scientometrics, 110/3: 1273-96. 